\title{
Feasibility of Treating Irradiated Bone with Intramedullary Delivered Autologous Mesenchymal Stem Cells
}

\author{
Bérengère Phulpin,, ${ }^{1,2}$ Gilles Dolivet,, ${ }^{1,2}$ Pierre-Yves Marie, ${ }^{3}$ Sylvain Poussier, ${ }^{3}$ \\ Sandrine Huger, ${ }^{4}$ Pierre Bravetti, ${ }^{5}$ Pierre Graff, ${ }^{4}$ Jean-Louis Merlin, ${ }^{2}$ \\ and Nguyen Tran ${ }^{3,6}$ \\ ${ }^{1}$ Head and Neck Surgery and Dental Units, Oncologic Surgery Department, Centre Alexis Vautrin, avenue de Bourgogne, \\ Brabois, 54511 Vandoeuvre-lès-Nancy, France \\ ${ }^{2}$ Tumor Biology Unit, EA 4421 SIGReTO, UHP Nancy-University and Centre Alexis Vautrin, avenue de Bourgogne, Brabois, \\ 54511 Vandoeuvre-lès- Nancy, France \\ ${ }^{3}$ NancyClotep, INSERM U961, Faculty of Medicine, UHP Nancy-University, avenue de la forêt de Haye, \\ 54500 Vandoeuvre-lès-Nancy, France \\ ${ }^{4}$ Radiotherapy Department, Centre Alexis Vautrin, avenue de Bourgogne, Brabois, 54511 Vandoeuvre-lès-Nancy, France \\ ${ }^{5}$ Oral Surgery Department, Faculty of Dentistry, 96 avenue Mal de Lattre de Tassigny BP.50208, 54004 Nancy, France \\ ${ }^{6}$ School of Surgery, INSERM U961, Faculty of Medicine, UHP Nancy-University, avenue de la forêt de Haye, \\ 54500 Vandoeuvre-lès-Nancy, France
}

Correspondence should be addressed to Nguyen Tran, nguyen.tran@medecine.uhp-nancy.fr

Received 3 May 2011; Accepted 20 June 2011

Academic Editor: Ji Wu

Copyright (c) 2011 Bérengère Phulpin et al. This is an open access article distributed under the Creative Commons Attribution License, which permits unrestricted use, distribution, and reproduction in any medium, provided the original work is properly cited.

Background. We aimed to explore (i) the short-term retention of intramedullary implanted mesenchymal stem cells BMSCs and (ii) their impact on the bone blood flow and metabolism in a rat model of hindlimb irradiation. Methods. Three months after 30 Gy irradiation, fourteen animals were referred into 2 groups: a sham-operated group $(n=6)$ and a treated group $(n=8)$ in which ${ }^{111}$ In-labelled BMSCs $\left(2 \times 10^{6}\right.$ cells $)$ were injected in irradiated tibias. Bone blood flow and metabolism were assessed by serial ${ }^{99 \mathrm{~m}} \mathrm{Tc}$-HDP scintigraphy and 1-wk cell retention by recordings of ${ }^{99 \mathrm{~m}} \mathrm{Tc} /{ }^{111} \mathrm{In}$ activities. Results. The amount of intramedullary implanted BMSCs was of $70 \%$ at $2 \mathrm{H}, 40 \%$ at $48 \mathrm{H}$, and $38 \%$ at $168 \mathrm{H}$. Bone blood flow and bone metabolism were significantly increased during the first week after cell transplantation, but these effects were found to reduce at 2-mo followup. Conclusion. Short-term cell retention produced concomitant enhancement in irradiated bone blood flow and metabolism.

\section{Introduction}

Radiotherapy has been proven to successfully treat local and regional neoplasic lesions but it may adversely impact on normal tissues [1]. High vulnerability to irradiation was already documented in various bone tissues (pelvis, sternum, vertebra, clavicle, femoral head, and mandible) [2] with subsequent deleterious effect on the bone metabolism and healing leading thereafter to infection, atrophy, pathological fractures, and osteoradionecrosis. For instance, the incidence of osteoradionecrosis after conventional radiotherapy ranges from $0.9 \%$ to $35 \%$ [3], with an increased risk when doses given to the mandible exceed $60 \mathrm{~Gy}$ [4]. Thus, irradiation of the mandible represents the most devastating radiotherapyinduced complication and might sometimes lead to surgical resection [5].

Since vascular ischemia is one of predictors of postirradiation degeneration, the inception of angiogenesis by implantation of bone marrow mesenchymal stem cells (BMSCs) might represent a therapeutic approach for rehabilitating the irradiated bone tissue. Such potentiality was already documented in diverse ischemic pathologies such 
as hindlimb ischemia [6] or myocardial infarction [7, 8]. Previous data regarding the role of BMSCs in the bone reconstruction have outlined their active contribution in the bone formation when seeded on various scaffolds [9, 10]. In a dog model of mandible segmental defect, the feasibility of bone reconstruction using morphologic and 3$D$ beta-tricalcium phosphate scaffold seeded with autologous BMSCs was highlighted by both bone formation and bone vascularization [10].

Experiments with BMSCs in the treatment or the prevention of radio-induced damage were reported on intestine [11, $12]$ and skin [13-15] using systemic [14-16] or local [11,13] delivery. Little is known however about the effect of BMSCs in irradiated bone tissue, and especially, the bioavailability and biodistribution of these cells within the targeted areas since their in vivo monitoring is now mandatory to further understand their benefice.

The study was designed to explore, in a rat model of hindlimb irradiation, the feasibility of rehabilitating irradiated tibial bone tissue by intramedullary implanted BMSCs. The assessment of BMSCs' retention and distribution were conducted up to 7 days following transplantation using ${ }^{111}$ In-oxine-labeling technique. Therapeutic effect on bone perfusion and metabolism was determined by serial ${ }^{99 \mathrm{~m}-}$-technetium hydroxymethane diphosphonate $\left({ }^{99 \mathrm{~m}} \mathrm{Tc}-\mathrm{HDP}\right)$ planar scintigraphy.

\section{Materials and Methods}

2.1. Animals. This study was conducted in 14 Wistar rats (initial body-weight of $410 \mathrm{~g}-460 \mathrm{~g}$ ). All experimental procedures were in accordance with our local ethical committee and with the regulations of the Animal Welfare Act of the National Institutes of Health Guide for the Care and Use of Laboratory Animals (NIH Publication no. 85-23, Revised 1996).

Three months after experiencing a hindlimb irradiation with a monodose of $30 \mathrm{~Gy}$ a ${ }^{99 \mathrm{~m}} \mathrm{Tc}-\mathrm{HDP}$ scintigraphy was performed. Thereafter, animals were referred into 2 groups: a control sham-operated group $(n=6)$ and a treated group $(n=8)$ in which ${ }^{111}$ In-labelled BMSCs $\left(2 \times 10^{6}\right.$ cells $)$ were intramedullary injected in irradiated tibial diaphysis; BMSCs being harvested before irradiation were cultured until passage 4 , and their mesenchymal phenotypes were evidenced by flow cytometry.

To evaluate changes in bone blood flow and metabolism, serial ${ }^{99 \mathrm{~m}}$ Tc-HDP planar scintigraphy was scheduled at 3 months after irradiation and at 2 months after the cell therapy. The early cell retention after the cell therapy was assessed by additional dual recordings of ${ }^{99} \mathrm{~m} \mathrm{Tc} /{ }^{11} \mathrm{in}$ activities done at 2 hours, 48 hours, and 168 hours after the cell injection.

2.2. Irradiation Procedures. Irradiation of the hindlimb was performed under general anesthesia as previously described [17]. Briefly, the animals were placed in prone position upon a thick polystyrene phantom and their hindlimb was immobilized by adhesive tape. The focus skin distance was $70 \mathrm{~cm}$, and the field size was $20 \times 30 \mathrm{~cm}$. The collimating block was positioned on a $0.5 \mathrm{~cm}$ thick acrylic platform to shield the body and only irradiated the exposition of the left hindlimb without the pelvis. Radiation with ${ }^{60} \mathrm{Co}$ was delivered in a vertical beam from a Theratron 780C X-ray machine delivering gamma rays of $1.25 \mathrm{MeV}$ energy and dose rate of $1.4 \mathrm{~Gy} / \mathrm{min}$.

\subsection{Noninvasive Imaging Procedures}

2.3.1. Sequential Planar Scintigraphy. Bone blood flow and metabolism were assessed using ${ }^{99 \mathrm{~m}} \mathrm{Tc}$-HDP. After the intravenous injection of $9 \mathrm{mCi}$ of ${ }^{99 \mathrm{~m}} \mathrm{Tc}-\mathrm{HDP}$ and under general anesthesia, the acquisition was recorded using a single-head gamma camera (Sopha DSX, SMV-GE) equipped with a $1.5 \mathrm{~mm}$ pinhole collimator ( $165 \mathrm{~mm}$ focal length, $44 \mathrm{~mm}$ radius of rotation) and with the following parameters: $256 \times 256$ matrix, 1.14 zoom, and $140( \pm 20 \%)$ keV energy window. Two acquisitions were performed: a dynamic HDP uptake (blood flow) consisted of images obtained at 1 second intervals for 60 seconds reflecting vascularity and a delayed ( 3 hours after) acquisition of HDP uptake reflecting osteoblastic metabolism [18].

Changes in accumulation of the tracer in irradiated bone and surrounding tissues were evaluated by measuring uptake within regions of interest (ROI) on the computerprocessed images software (Dysplay, Console Vision, General Electric). Values were expressed as percentage (\%) of total body activity.

2.3.2. Dual ${ }^{111} \mathrm{In} /{ }^{99 m} T c$ Scintigraphy. Planar scintigraphic images of the body distribution of ${ }^{111}$ In-labeled BMSCs were provided by the same single-head gamma camera (Sopha DSX, SMV-GE) already described $[8,19]$. Two $20 \%$ energy windows centered on the $172 \mathrm{KeV}$ and $246 \mathrm{KeV}$ photopeaks of ${ }^{111}$ In were applied. The initial image was recorded $2 \mathrm{H}$ after cell transplantation during a 15 -min period and then at day $2(48 \mathrm{H})$ and day $7(168 \mathrm{H})$ during time periods of 20 and $40 \mathrm{~min}$, respectively. ${ }^{111}$ In activity from each image was expressed relative to the total injected activity (total body activity determined at $2 \mathrm{H}$ ) and after additional corrections for the physical decay of ${ }^{111}$ In (2.9 days).

\subsubsection{BMSC Isolation, Cell Culture and Flow Cytometry.} Autologous bone marrow cells, harvested from the left tibias by punction, were cultured and expanded as previously described in detail elsewhere [19,20]. Briefly, aspired whole bone marrow cells were suspended in Iscove's modified Dulbecco's culture medium (Life Technologies, Cergy Pontoise, France) containing 10\% fetal bovine serum (Life Technologies, Cergy Pontoise, France), $0.1 \mathrm{mmol} / \mathrm{L} \beta$ mercaptoethanol (Sigma, France), $100 \mathrm{U} / \mathrm{mL}$ penicillin, and $100 \mu \mathrm{g} / \mathrm{mL}$ streptomycin. The cells were grown in a $5 \% \mathrm{hu}-$ midified $\mathrm{CO}_{2}$ atmosphere at $37^{\circ} \mathrm{C}$, and the medium was changed every 2 days.

To ascertain the mesenchymal phenotype of transplanted BMSCs, the expression of CD34, CD44, CD45, and CD90 surface antigens of cells prior to implantation (passage 4) was 
Case 1

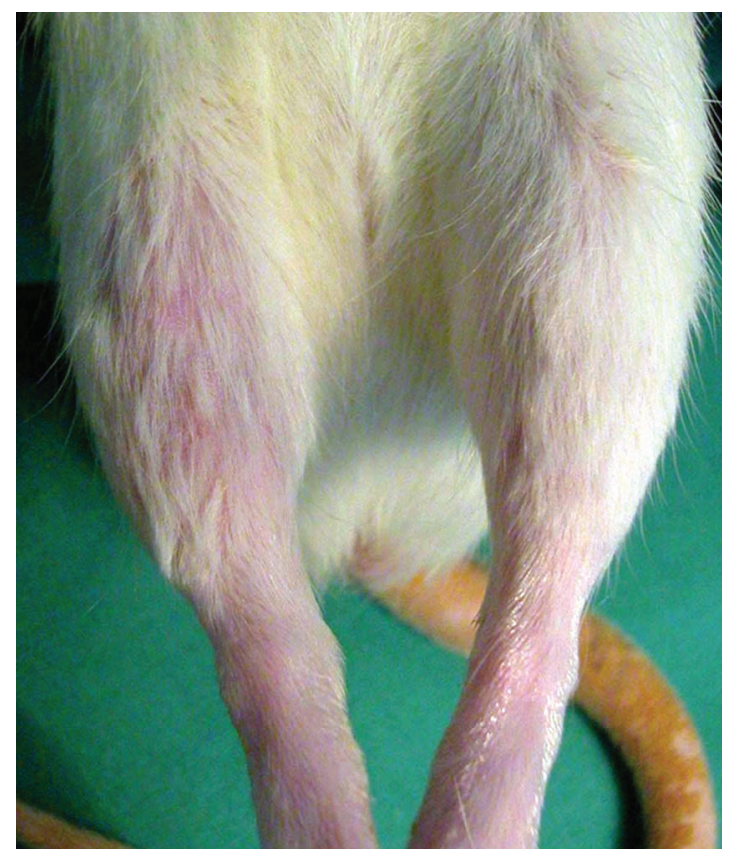

Case 2

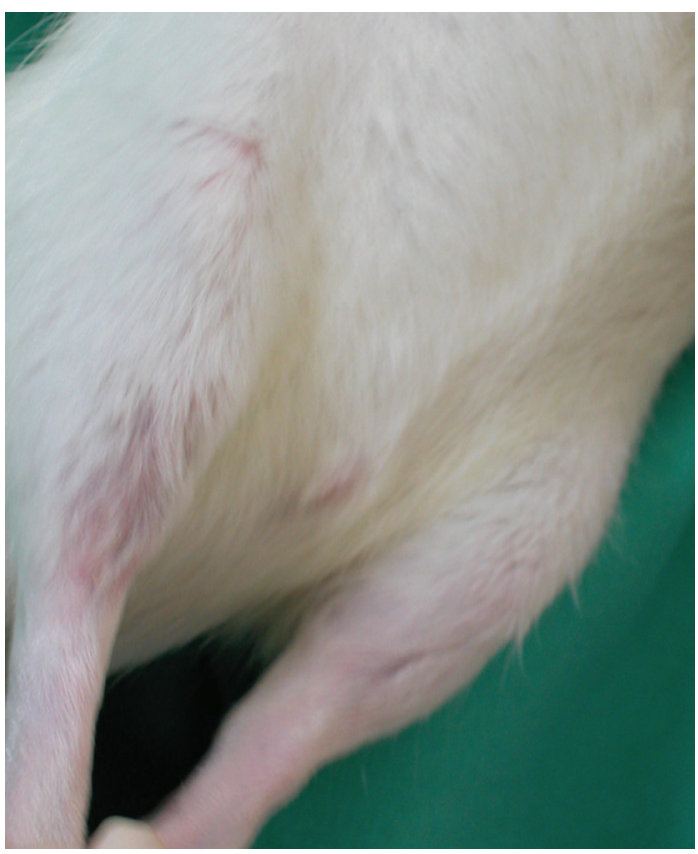

(a) Macroscopic images
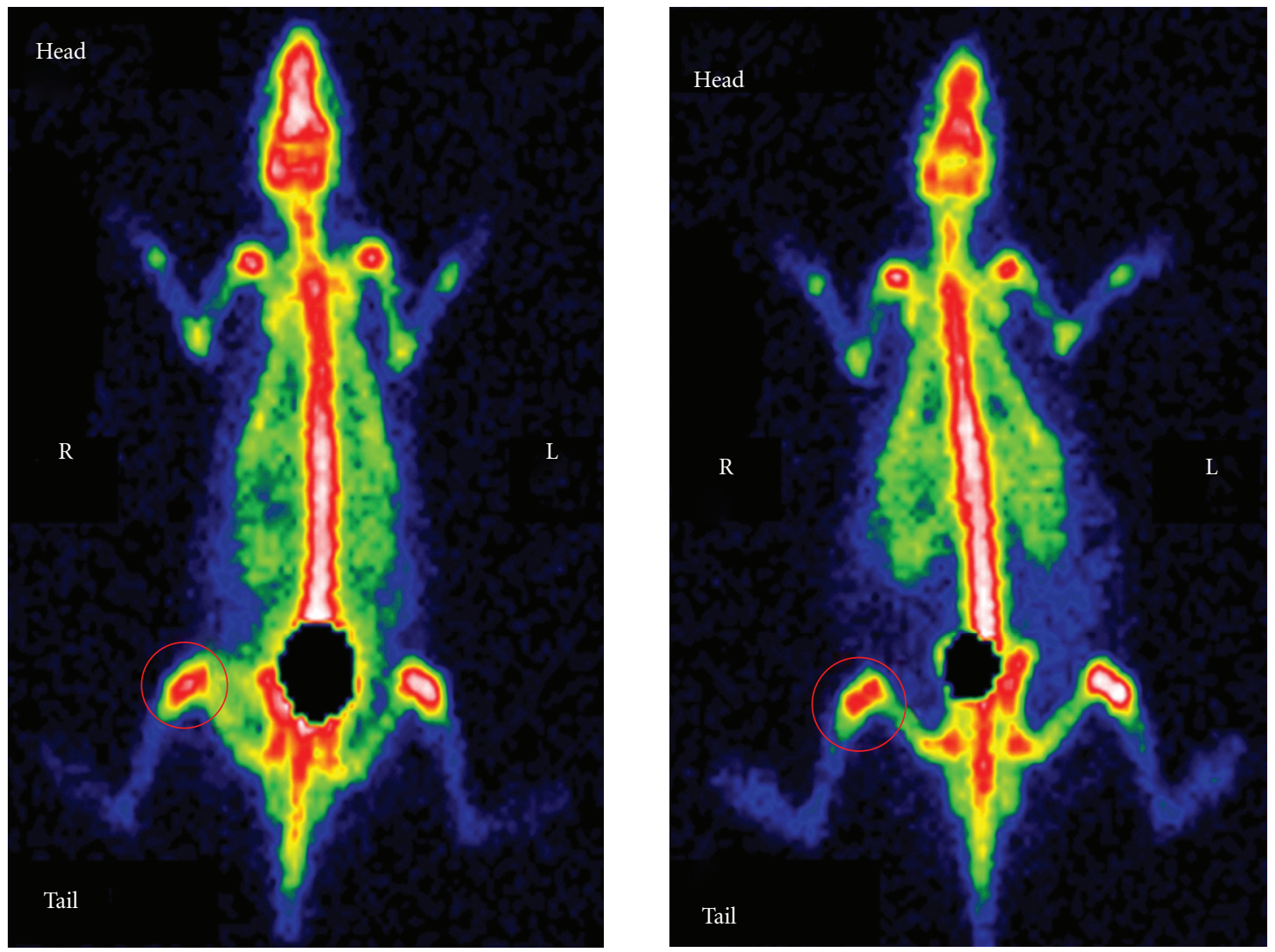

(b) Scintigraphic images

Figure 1: Animal model of hindlimb irradiation. (a) Examples of pictures showing alopecia of the hindlimb 3 months after irradiation at a monodose of $30 \mathrm{~Gy}$. (b) Examples of scintigraphic imaging showing the decrease of bone ${ }^{99 \mathrm{~m}} \mathrm{Tc}-\mathrm{HDP}$ on the irradiated hindlimb 3 months after irradiation. 

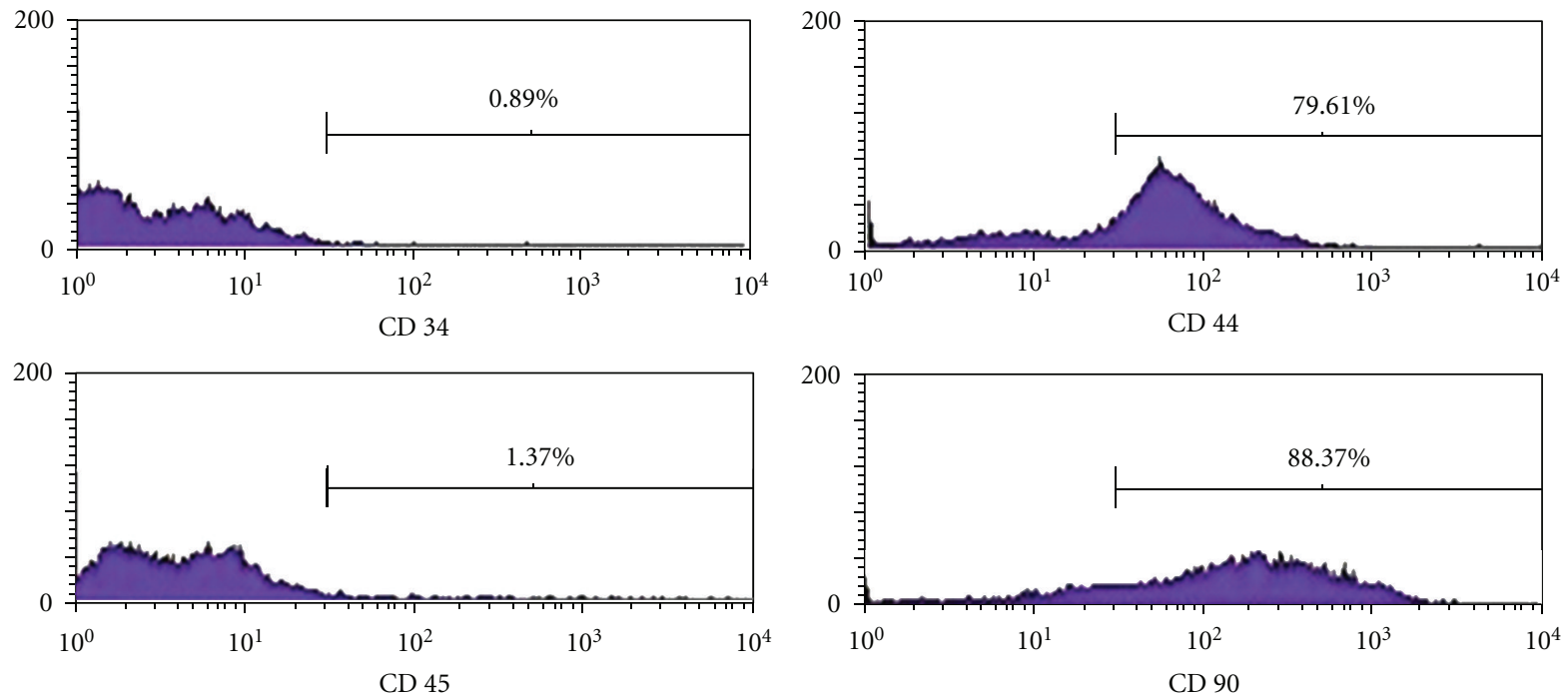

(a)
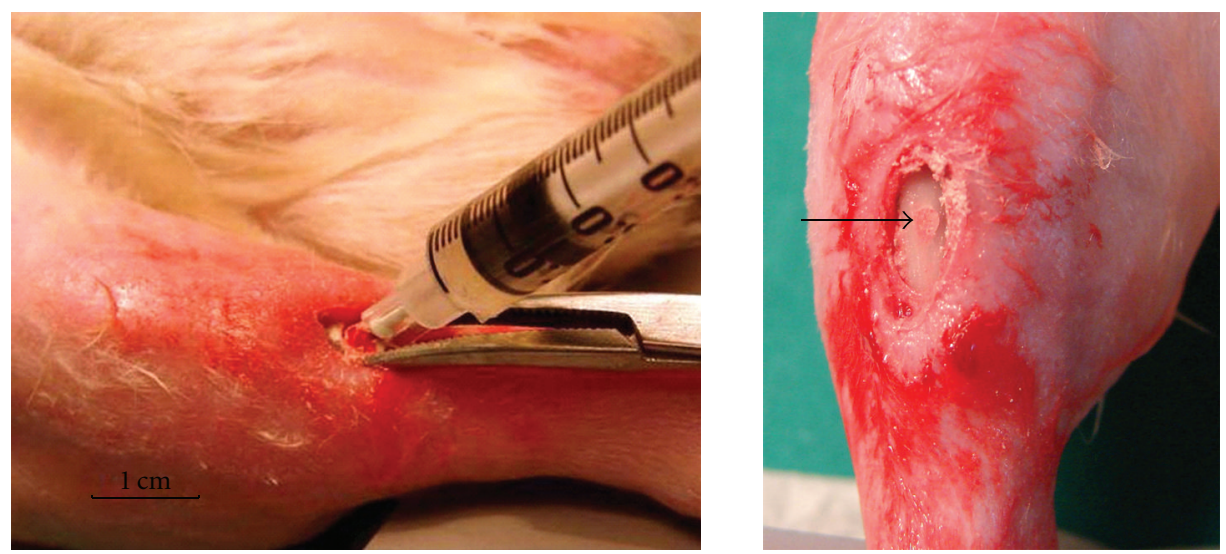

(b)

FIGURE 2: Mesenchymal quality of the engrafted BMSCs and injection procedure. (a) flow cytometry data depicting several conventional surface antigens of mesenchymal cells (CD34-, CD44+, CD45-, and CD90+) prior to implantation (passage 4). (b) technique of intramedullary injection (left panel) and on the right panel, the arrow indicates the bandage on the surgical site after BMSC engraftment.

TABLE 1: Pretherapeutic value of ${ }^{99 \mathrm{~m}}$ Tc-HDP bone uptake of the rat hindlimbs. Results were expressed as percentage of total corporel activity.

\begin{tabular}{lccccc}
\hline & & \multicolumn{2}{c}{ Group 1 } & \multicolumn{2}{c}{ Group 2 } \\
& & Nonirradiated hindlimb & Irradiated hindlimb & Nonirradiated hindlimb & Irradiated hindlimb \\
\hline \multirow{3}{*}{ Bone blood flow } & Knee & $7.9 \pm 1.0$ & $8.3 \pm 1.2$ & $8.1 \pm 1.3$ & $8.3 \pm 1.3$ \\
& Tibia & $3.82 \pm 0.6$ & $3.0 \pm 0.8^{*}$ & $3.79 \pm 1.0$ & $3.2 \pm 0.3^{*}$ \\
& Foot & $2.4 \pm 0.7$ & $2.6 \pm 0.8$ & $2.7 \pm 0.6$ & $2.6 \pm 0.7$ \\
\hline \multirow{3}{*}{ Bone osteoblastic metabolism } & Knee & $10.3 \pm 3.0$ & $9.9 \pm 1.7$ & $11.3 \pm 4.9$ & $8.9 \pm 1.9$ \\
& Tibia & $2.2 \pm 0.2$ & $2.1 \pm 0.1$ & $2.3 \pm 0.2$ & $2.0 \pm 0.3$ \\
& Foot & $3.8 \pm 0.7$ & $3.3 \pm 1.0$ & $3.7 \pm 3.0$ & $3.5 \pm 1.4$ \\
\hline
\end{tabular}

${ }^{*} P<0.05$ versus contralateral nonirradiated legs.

analysed using flow cytometry method (FACSCalibur; Becton Dickinson, Meylan, France) and the Cellquest software (Becton Dickinson, Meylan, France) [20].

\subsection{Intramedullary Implantation of Radiolabeled BMSCs}

2.4.1. Cell Labeling and Cell Transplantation. As already described $[7,8]$, BMSCs $\left(2 \times 10^{6}\right.$ cells $\left./ \mathrm{mL}\right)$ were trypsinised and incubated at $37^{\circ} \mathrm{C}$ with $15 \mathrm{MBq}$ of ${ }^{111} \mathrm{In}$-oxine (Mallinckrodt Medical B.V., Holland) during a 10-min period, the labelling 
TABLE 2: Post-therapeutic value of ${ }^{99 \mathrm{~m}} \mathrm{Tc}-\mathrm{HDP}$ bone uptake of the irradiated hindlimbs. Results were expressed as relative to the unirradiated hindlimb.

\begin{tabular}{|c|c|c|c|c|c|}
\hline & & Hindlimb & posttherapeutic $48 \mathrm{H}$ & posttherapeutic $168 \mathrm{H}$ & posttherapeutic 2 months \\
\hline \multirow{6}{*}{ Bone blood flow } & \multirow{2}{*}{ Knee } & Irradiated untreated & $-0.40 \pm 1.30$ & $-0.76 \pm 1.62$ & $+0.16 \pm 0.91$ \\
\hline & & Irradiated treated & $-0.30 \pm 0.89$ & $-1.18 \pm 0.87$ & $+0.20 \pm 0.98$ \\
\hline & \multirow{2}{*}{ Tibia } & Irradiated untreated & $+0.95 \pm 1.43$ & $+0.21 \pm 1.45$ & $-0.01 \pm 0.49$ \\
\hline & & Irradiated treated & $+2.00 \pm 0.68^{*}$ & $+0.70 \pm 1.03^{*}$ & $+0.40 \pm 0.53$ \\
\hline & \multirow{2}{*}{ Foot } & Irradiated untreated & $+1.05 \pm 1.12$ & $+0.26 \pm 1.57$ & $+0.46 \pm 0.31$ \\
\hline & & Irradiated treated & $+1.64 \pm 1.25$ & $+1.02 \pm 0.96$ & $+0.56 \pm 0.90$ \\
\hline \multirow{6}{*}{ Bone osteoblastic metabolism } & \multirow{2}{*}{ Knee } & Irradiated untreated & $-2.12 \pm 1.25$ & $-1.06 \pm 1.06$ & $-1.21 \pm 1.13$ \\
\hline & & Irradiated treated & $-1.68 \pm 1.43$ & $-1.57 \pm 1.44$ & $-1.16 \pm 0.98$ \\
\hline & \multirow{2}{*}{ Tibia } & Irradiated untreated & $+0.28 \pm 0.85$ & $-0.04 \pm 0.67$ & $-0.01 \pm 0.66$ \\
\hline & & Irradiated treated & $+0.77 \pm 0.56^{*}$ & $+0.47 \pm 0.58^{*}$ & $+0.07 \pm 0.56$ \\
\hline & \multirow{2}{*}{ Foot } & Irradiated untreated & $+0.36 \pm 0.89$ & $+0.01 \pm 1.19$ & $+0.07 \pm 0.59$ \\
\hline & & Irradiated treated & $+1.07 \pm 1.21$ & $+0.58 \pm 0.62$ & $+0.43 \pm 0.96$ \\
\hline
\end{tabular}

${ }^{*} P<0.05$ versus contralateral nonirradiated legs.

process being stopped by 5 -min centrifugation at $950 \mathrm{~g}$. This 10 -min incubation period was previously found to result in both a sufficiently high labeling efficiency (69\%) and absence of significant deterioration of cell viability (96\%) [8].

After stab incision, a $1 \mathrm{~mm}$ diameter drill hole was performed perpendicularly to the orientation of the tibial cortical bone. The ${ }^{111} \mathrm{In}$-labelled cells were conditioned in a $1 \mathrm{~mL}$ syringe $\left(2 \times 10^{6}\right.$ cells in $\left.50 \mu \mathrm{L}\right)$ and were injected through the mini-invasive perforation into the bone marrow of the left tibia. To prevent leakage of transplanted cells in the surrounding tissues a biocompatible bandage (IRM Dentsply 78467 Konstanz Germany) was positioned over the drilling site.

2.4.2. Statistics. The statistical analysis was carried out with the Statistical Package SPSS version 14.0 (SPSS, Inc., Chicago, Ill, USA). We used Mann-Whitney tests for the unpaired comparisons and Wilcoxon tests for the paired comparisons in each group. For each test, a $P$ value $<0.05$ was considered to be indicative of a significant difference.

\section{Results}

3.1. Animal Model of Hindlimb Irradiation and Pretherapeutic Data. No animal died throughout the study's period. The 30-Gy irradiation induced 3-4 weeks later a persisting alopecia in the irradiated hindlimb (Figure 1(a)) without affecting however the daily locomotor activities of those animals.

At 2-mo scintigraphic imaging, radiation-induced bone defects appear as areas of attenuation of signal intensity covering the irradiated lower limb, with pronounced effect in the tibia (see Figure 1(b), e.g.). The pretherapeutic data of the group control and the cell-treated group were resumed in the Table 1. In both groups, compared with the total body activity, irradiation of the hindlimb produced similar alteration in tibial values of bone perfusion blood flow (early uptake of ${ }^{99 \mathrm{~m}} \mathrm{Tc}-\mathrm{HDP}$ ) and bone osteoblastic metabolism (late uptake of $\left.{ }^{99 \mathrm{~m}} \mathrm{Tc}-\mathrm{HDP}\right)$. For example, bone perfusion blood flow was $3.2 \pm 0.8 \%$ at the irradiated tibia compared to $3.8 \pm 1.0 \%$ found in the healthy one $(P<0.05)$. A slight decrease in bone metabolism of circa $10 \%$ was found in irradiated tibias, but values did not reach statistical significance $(2.0 \pm 0.3 \%$ versus $2.3 \pm 0.6 \%$ found in healthy counterparts).

\subsection{Cell Identification, Short-Term In vivoTracking, and Post- therapeutic Data}

3.2.1. Cell Identification Prior to the Cell Grafting. Flow cyto-metry analyses (Figure 2(a)) showed that the engrafted BMSCs of passage 4 expressed strong expression of CD44 and CD90 surface antigens $(>80 \%)$. Thus, these cells were negative for CD45 and CD34 (percentage of positive cells were $2.41 \pm 2.47 \%$ for CD45 and $1.99 \pm 2.72 \%$ for CD34). These data were consistent with our previous studies [20] and in accordance with criteria defined by the International Society for Cellular Therapy (ISCT) [21].

3.2.2. Effect of BMSCs on Bone Blood Flow and Bone Metabolism in Irradiated Hindlimb. ${ }^{99 \mathrm{~m}} \mathrm{Tc}-\mathrm{HDP}$ scintigraphic examinations performed after intramedullary implantation of BMSCs have documented, especially in the tibial area, a significant rise in both bone blood flow and bone metabolism during the posttherapeutic first week (Table 2 and Figure 5). At 48 hours, the bone blood flow found in cell-treated tibias was $4.7 \pm 0.7 \%$ corresponding to an enhancement of $62 \%$ compared to basal pretherapeutic values $(P<0.01)$. Similarly, the bone metabolism was $35 \%$ higher than that measured before treatment, values were $2.7 \pm 0.5 \%(P<0.01$ versus pretherapeutic data $)$. These effects persisted at 7 days, bone blood flow was $4.5 \pm 1.0 \%$ $(P<0.01$ versus pretherapeutic data), and bone metabolism was $2.6 \pm 0.6 \%(P<0.05$ versus pretherapeutic data). At $2-$ mo followup, these uptake values were found to be down to $3.1 \pm 1.4 \%$ for the bone blood flow and $1.7 \pm 0.3 \%$ for the bone metabolism. 

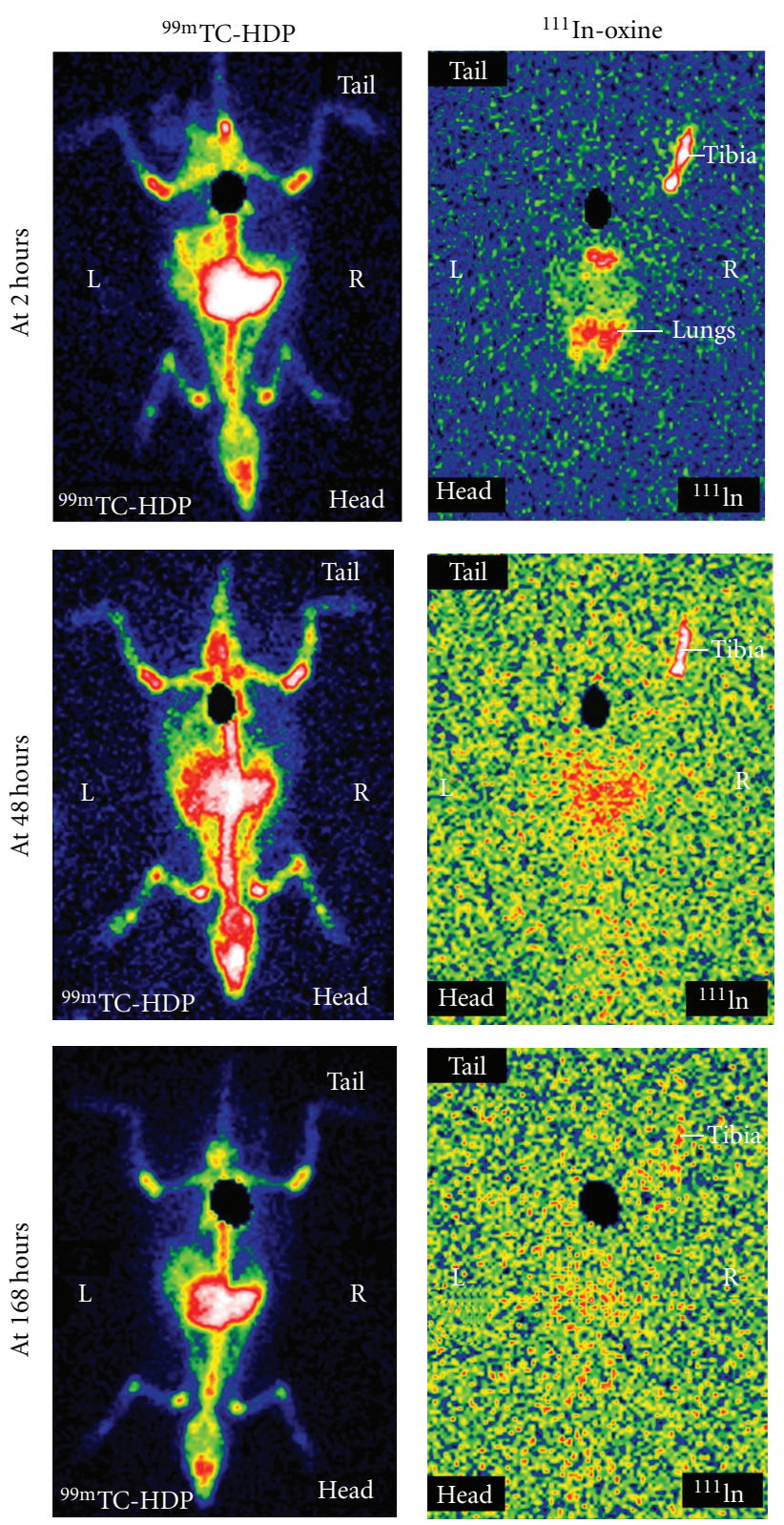

FIGURE 3: Example of scintigrams from ${ }^{111} \mathrm{In} /{ }^{99 \mathrm{~m}} \mathrm{Tc}$ dual-SPECT showing the short-term retention of ${ }^{111}$ In-oxine-labeled BMSCs following intramedullary injection.

\section{Discussion}

Damage of normal tissue secondary to radiotherapy is still a major problem in cancer treatment. Stem cell therapy seems to be a new treatment option in radio-induced tissue abnormalities [22-24], providing a mean to reduce related side effects and to improve the quality of life of patients. In this study, we investigated the feasibility of BMSCs when injected intramedullary in an experimental rat model of radio-induced degeneration recently described by our group [17].

In the present study, ${ }^{111}$ In-oxine labelling of BMSCs was successfully used to follow bone retention and body

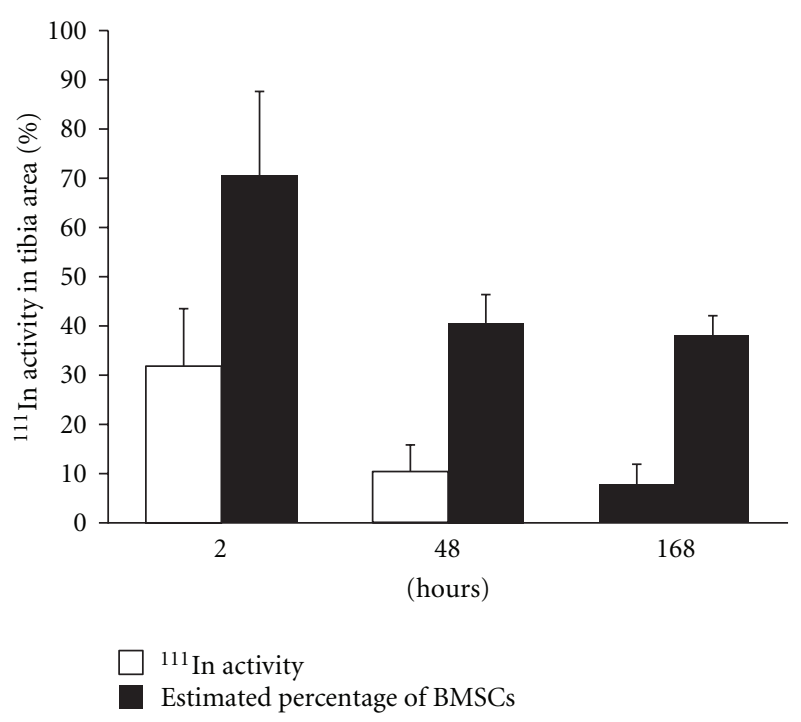

FIGURE 4: In vivo evolution of ${ }^{111}$ In activity found in the tibia during the 7-day followup and estimation of the percentage of BMSCs retained within the injection site. Calculation of BMSCs retention in the tibia was defined as the ration of the mean radioactivity in the tibia to the mean radioactivity that remained in BMSCs at each time point.

distribution of BMSCS when injected intramedullary within irradiated bone. ${ }^{111}$ In-labelled cells have been widely used in humans in localizing areas of inflammation by imaging the leukocyte distribution [25]. Furthermore, ${ }^{111}$ In-labelling techniques have been applied in various experimental settings in animal to analyse the migration of dendritic cells [26], the biodistribution of transplanted hepatocytes [27], and of injected MSCs in animals model of heart or lung disease $[7,28]$. As previously described [7], the technique used here reached a high efficiency $(69 \%)$ with a low toxicity (viability $>95 \%$ ). In addition, it has been previously demonstrated that the leakage of ${ }^{111}$ In from labelled cells resulted in a high ${ }^{111}$ In uptake in the liver and spleen and usually had hepatobiliary and renal excretion pathways [7, 29]. This is in accordance with our observations, and no ${ }^{111}$ In radioactivity was found in bones outside the area of injection. Approximately $70 \%$ of grafted cells could be estimated to be retained within bone damaged area 2 hours after transplantation. The "disappearance" of radiolabeled grafted cell may be explained by the method used for BMSCs injection which could be associated with a leakage of BMSCs from the injection site before bandage and residual BMSCs in the injection syringes. These data are fully consistent with those of the study of Tran et al. [7], where approximately $60 \%$ of ${ }^{111}$ In labeled BMSCs were still present 2 hours after direct transplantation in a necrotic rat myocardium and were retained within the heart throughout the 7 days of followup. In the present study, after 48 hours, BMSCs number decreased to approximately $40 \%$ and remained un-changed until the 7th day. The mechanism responsible for cell loss during the first two days remains to be explored. These results highlighted that at short term, the engrafted BMSCs 


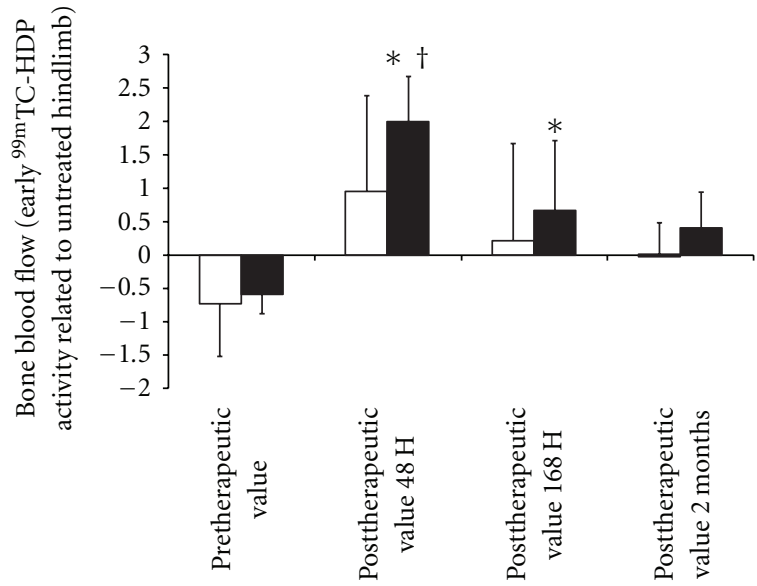

(a)

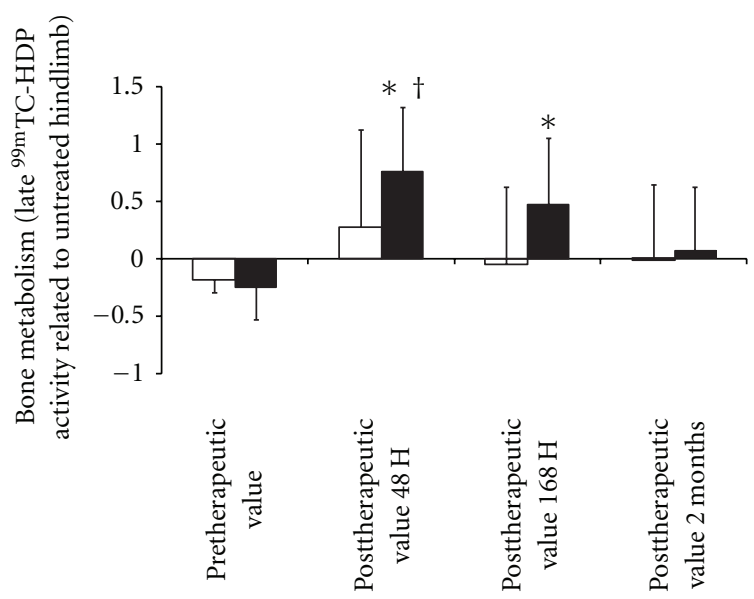

(b)

Figure 5: Two-month evolution of bone flood flow (a) and bone osteoblastic metabolism (b) in irradiated tibias treated with BMSCs (dark columns) and control (white columns), values being expressed as relative to baseline ( $\%$ of uptake variations with regard to untreated hindlimb values). ${ }^{*} P<0.05$ versus pretherapeutic data, ${ }^{\dagger} P<0.05$ versus control group.

remain localized within the area of injection into irradiated bone.

Many studies of cell therapy using mesenchymal stem cells $[14,16]$, used the systemic injection as modality of administration. In comparison, using local injection, cells engraftment seems to be better. For example, in François et al.'s study [14], rats were transplanted with a dose of $5 \times 10^{6}$ BMSCs 24 hours after irradiation of the hindlimb at a single dose of $26.5 \mathrm{~Gy}$. Fifteen days later, the implantation rates of BMSCs in bone and bone marrow were, respectively, approximately $12.5 \%$ and less than $0.25 \%$. The major limitation of this approach is constituted by the very low number of BMSCs that home to the site of injury [30]. A possible reason for the inefficient engraftment and homing could be the entrapment of BMSCs in the lungs [31]. Moreover, vascular ischemia and fibrosis, characteristic injury of irradiated tissue $[1,32]$, may prevent homing and engraftment of BMSCs.
After cell therapy, the bone blood flow and bone metabolism evolved similarly, and a significant increase of these values was observed during the seven days following the BMSCs engraftment. The influence of the surgical procedure used in the present study would require further investigation, especially regarding the role of the inflammation cells response and the local recruitment of mesenchymal stem cells [33] that should have been induced by the wound healing after drilling the cortical bone. However, the benefit obtained seems to be transient since 2 months after cell therapy, blood flow time and bone uptake of ${ }^{99 \mathrm{~m}} \mathrm{Tc}$ HDP did not differ significantly from data measured in ungrafted animals irradiated at $30 \mathrm{~Gy}$. This result slightly differs from those achieved in our previous study [34], in which autologous fat was used as source of mesenchymal stem cell and grafted within irradiated area, inducing clinical benefit that appeared to be linked to the improvement of vascular network and disappearance of necrotic area. Additional results demonstrating the potency of BMSCs therapy in irradiated tissues were recently reported [35] describing a case of regenerative reconstruction of a terminal stage of osteoradionecrosis with BMSCs and progenitor cells. Another explanation that stands for the short effect of engrafted BMSCs might be related to the native hypoxic microenvironment of the medullar area target of the bone. The BMSCs used here were expanded according to most of the conventional cell culture procedures, that is, in normoxic condition $\left(21 \% \mathrm{O}_{2}\right)$. Although they have mesenchymal characteristics, recent works from our group [36] and others [37] have suggested that BMSC, when cultured under 5\% $\mathrm{O}_{2}$ rather than under $21 \% \mathrm{O}_{2}$, had better growth advantage in long-term cell expansion. Thus, the hypoxic BMSC expressed more adhesion and extracellular matrix molecules and displayed more plasticity features. It is then possible that different in vitro conditions during the cell selection and expansion might lower their ability to repair when reimplanted in native environment. This hypothesis needs further experimental evidences.

\section{Conclusion}

In conclusion, the present study shows the feasibility of the intramedullary implantation of BMSCs in the attempt to rehabilitate the irradiated bone. Our data suggested that BMSCs appear to remain around the injection site, without evident body redistribution, for at least a 7-day period along with a transient benefice on bone blood flow and bone metabolism. Further experiments are required to evaluate their long-term beneficial effect.

\section{Conflict of Interests}

The authors declare that there is no conflict of interests.

\section{Acknowledgment}

This work was granted by the Lorraine Comity of the French League against cancers (Ligue Française contre le cancer, Comités Lorrains). 


\section{References}

[1] H. B. Stone, C. N. Coleman, M. S. Anscher, and W. H. McBride, "Effects of radiation on normal tissue: consequences and mechanisms," The Lancet Oncology, vol. 4, no. 9, pp. 529536, 2003.

[2] M. A. Engleman, G. Woloschak, and W. Small Jr., "Radiationinduced skeletal injury," Cancer Treatment and Research, vol. 128, pp. 155-169, 2006.

[3] T. Reuther, T. Schuster, U. Mende, and A. C. Kübler, "Osteoradionecrosis of the jaws as a side effect of radiotherapy of head and neck tumour patients - a report of a thirty year retrospective review," International Journal of Oral and Maxillofacial Surgery, vol. 32, no. 3, pp. 289-295, 2003.

[4] B. A. Jereczek-Fossa and R. Orecchia, "Radiotherapy-induced mandibular bone complications," Cancer Treatment Reviews, vol. 28, no. 1, pp. 65-74, 2002.

[5] B. R. Chrcanovic, P. Reher, A. A. Sousa, and M. Harris, "Osteoradionecrosis of the jaws-a current overview-part 1: physiopathology and risk and predisposing factors," Oral and Maxillofacial Surgery, vol. 14, no. 1, pp. 3-16, 2010.

[6] T. Iwase, N. Nagaya, T. Fujii et al., "Comparison of angiogenic potency between mesenchymal stem cells and mononuclear cells in a rat model of hindlimb ischemia," Cardiovascular Research, vol. 66, no. 3, pp. 543-551, 2005.

[7] N. Tran, Y. Li, F. Maskali et al., "Short-term heart retention and distribution of intramyocardial delivered mesenchymal cells within necrotic or intact myocardium," Cell Transplantation, vol. 15, no. 4, pp. 351-358, 2006.

[8] N. Tran, S. Poussier, P. R. Franken et al., "Feasibility of in vivo dual-energy myocardial SPECT for monitoring the distribution of transplanted cells in relation to the infarction site," European Journal of Nuclear Medicine and Molecular Imaging, vol. 33, no. 6, pp. 709-715, 2006.

[9] A. Muraglia, I. Martin, R. Cancedda, and R. Quarto, "A nude mouse model for human bone formation in unloaded conditions," Bone, vol. 22, no. 5, pp. 131S-134S, 1998.

[10] Y. He, Z. Y. Zhang, H. G. Zhu, W. Qiu, X. Jiang, and W. Guo, "Experimental study on reconstruction of segmental mandible defects using tissue engineered bone combined bone marrow stromal cells with three-dimensional tricalcium phosphate," Journal of Craniofacial Surgery, vol. 18, no. 4, pp. 800-805, 2007.

[11] K. Kudo, Y. Liu, K. Takahashi et al., "Transplantation of mesenchymal stem cells to prevent radiation-induced intestinal injury in mice," Journal of Radiation Research, vol. 51, no. 1, pp. 73-79, 2010.

[12] A. Sémont, M. Mouiseddine, A. François et al., "Mesenchymal stem cells improve small intestinal integrity through regulation of endogenous epithelial cell homeostasis," Cell Death and Differentiation, vol. 17, no. 6, pp. 952-961, 2010.

[13] D. Agay, H. Scherthan, F. Forcheron et al., "Multipotent mesenchymal stem cell grafting to treat cutaneous radiation syndrome: development of a new minipig model," Experimental Hematology, vol. 38, no. 10, pp. 945-956, 2010.

[14] S. François, M. Bensidhoum, M. Mouiseddine et al., "Local irradiation not only induces homing of human mesenchymal stem cells at exposed sites but promotes their widespread engraftment to multiple organs: a study of their quantitative distribution after irradiation damage," Stem Cells, vol. 24, no. 4, pp. 1020-1029, 2006.
[15] S. François, M. Mouiseddine, N. Mathieu et al., "Human mesenchymal stem cells favour healing of the cutaneous radiation syndrome in a xenogenic transplant model," Annals of Hematology, vol. 86, no. 1, pp. 1-8, 2007.

[16] K. X. Hu, Q. Y. Sun, M. Guo, and H. S. Ai, "The radiation protection and therapy effects of mesenchymal stem cells in mice with acute radiation injury," British Journal of Radiology, vol. 83, no. 985, pp. 52-58, 2010.

[17] B. Phulpin, G. Dolivet, P.-Y. Marie et al., "Re-assessment of chronic radio-induced tissue damage in a rat hindlimb model," Experimental and Therapeutic Medicine, vol. 1, pp. 553-560, 2010.

[18] H. Schirrmeister, A. Guhlmann, J. Kotzerke et al., "Early detection and accurate description of extent of metastatic bone disease in breast cancer with fluoride ion and positron emission tomography," Journal of Clinical Oncology, vol. 17, no. 8, pp. 2381-2389, 1999.

[19] N. Tran, P. R. Franken, F. Maskali et al., "Intramyocardial implantation of bone marrow-derived stem cells enhances perfusion in chronic myocardial infarction: dependency on initial perfusion depth and follow-up assessed by gated pinhole SPECT," Journal of Nuclear Medicine, vol. 48, no. 3, pp. 405-412, 2007.

[20] L. Zhang, N. Tran, H. Q. Chen et al., "Time-related changes in expression of collagen types I and III and of tenascin-C in rat bone mesenchymal stem cells under co-culture with ligament fibroblasts or uniaxial stretching," Cell and Tissue Research, vol. 332, no. 1, pp. 101-109, 2008.

[21] M. Dominici, K. Le Blanc, I. Mueller et al., "Minimal criteria for defining multipotent mesenchymal stromal cells. The International Society for Cellular Therapy position statement," Cytotherapy, vol. 8, no. 4, pp. 315-317, 2006.

[22] C. Hou, X. Wu, and X. Jin, "Autologous bone marrow stromal cells transplantation for the treatment of secondary arm lymphedema: a prospective controlled study in patients with breast cancer related lymphedema," Japanese Journal of Clinical Oncology, vol. 38, no. 10, pp. 670-674, 2008.

[23] R. P. Coppes, A. van der Goot, and I. M. A. Lombaert, "Stem cell therapy to reduce radiation-induced normal tissue damage," Seminars in Radiation Oncology, vol. 19, no. 2, pp. 112121, 2009.

[24] E. Bey, M. Prat, P. Duhamel et al., "Emerging therapy for improving wound repair of severe radiation burns using local bone marrow-derived stem cell administrations," Wound Repair and Regeneration, vol. 18, no. 1, pp. 50-58, 2010.

[25] W. Becker and J. Meller, "The role of nuclear medicine in infection and inflammation," The Lancet Infectious Diseases, vol. 1, no. 5, pp. 326-333, 2001.

[26] D. Blocklet, M. Toungouz, R. Kiss et al., "111In-oxine and 99mTc-HMPAO labelling of antigen-loaded dendritic cells: in vivo imaging and influence on motility and actin content," European Journal of Nuclear Medicine and Molecular Imaging, vol. 30, no. 3, pp. 440-447, 2003.

[27] N. I. Bohnen, M. Charron, J. Reyes et al., "Use of indium-111labeled hepatocytes to determine the biodistribution of transplanted hepatocytes through portal vein infusion," Cli-nical Nuclear Medicine, vol. 25, no. 6, pp. 447-450, 2000.

[28] K. Takemiya, H. Kai, H. Yasukawa, N. Tahara, S. Kato, and T. Imaizumi, "Mesenchymal stem cell-based prostacyclin synthase gene therapy for pulmonary hypertension rats," Basic Research in Cardiology, vol. 105, no. 3, pp. 409-417, 2010. 
[29] J. Kuyama, A. McCormack, A. J. T. George et al., "Indium-111 labelled lymphocytes: isotope distribution and cell division," European Journal of Nuclear Medicine, vol. 24, no. 5, pp. 488496, 1997.

[30] R. Marino, C. Martinez, K. Boyd, M. Dominici, T. J. Hofmann, and E. M. Horwitz, "Transplantable marrow osteoprogenitors engraft in discrete saturable sites in the marrow microenvironment," Experimental Hematology, vol. 36, no. 3, pp. 360-368, 2008.

[31] B. M. Abdallah and M. Kassem, "Human mesenchymal stem cells: from basic biology to clinical applications," Gene Therapy, vol. 15, no. 2, pp. 109-116, 2008.

[32] M. Martin, S. Delanian, V. Sivan et al., "Radiation-induced superficial fibrosis and TGF-alpha 1," Cancer/Radiothérapie, vol. 4, no. 5, pp. 369-384, 2000.

[33] L. Geris, A. Gerisch, J. V. Sloten, R. Weiner, and H. V. Oosterwyck, "Angiogenesis in bone fracture healing: a bioregulatory model," Journal of Theoretical Biology, vol. 251, no. 1, pp. 137158, 2008.

[34] B. Phulpin, P. Gangloff, N. Tran, P. Bravetti, J. L. Merlin, and G. Dolivet, "Rehabilitation of irradiated head and neck tissues by autologous fat transplantation," Plastic and Reconstructive Surgery, vol. 123, no. 4, pp. 1187-1197, 2009.

[35] J. J. Mendonça and P. Juiz-Lopez, "Regenerative facial reconstruction of terminal stage osteoradionecrosis and other advanced craniofacial diseases with adult cultured stem and progenitor cells," Plastic and Reconstructive Surgery, vol. 126, no. 5, pp. 1699-1709, 2010.

[36] L. Basciano, C. Nemos, B. Foliguet et al., "Long term culture of mesenchymal stem cells in hypoxia promotes a genetic program maintaining their undifferentiated and multipotent status," BMC Cell Biology, vol. 12, article 12, 2011.

[37] C. Holzwarth, M. Vaegler, F. Gieseke et al., "Low physiologic oxygen tensions reduce proliferation and differentiation of human multipotent mesenchymal stromal cells," BMC Cell Biology, vol. 11, article 11, 2010. 

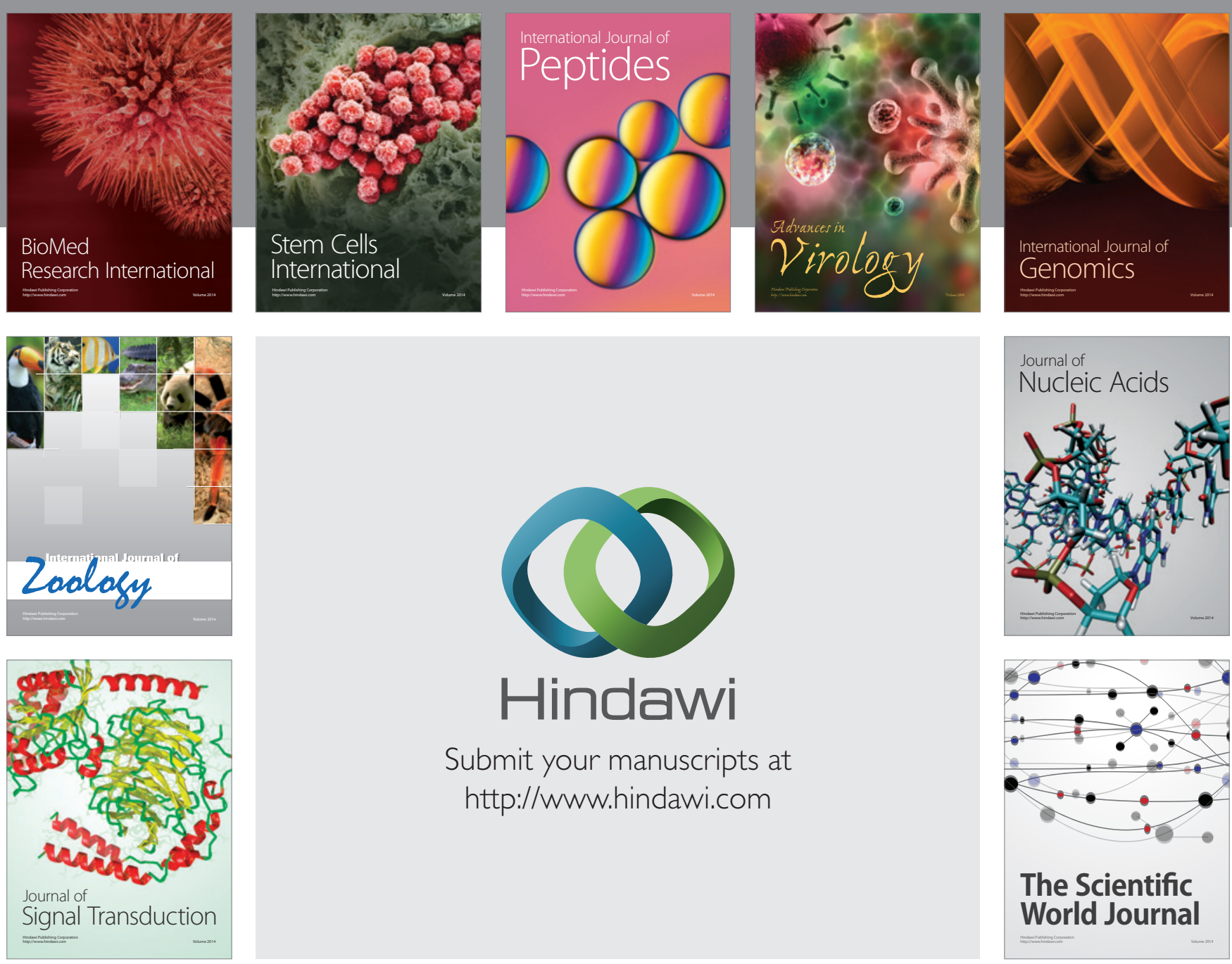

Submit your manuscripts at

http://www.hindawi.com
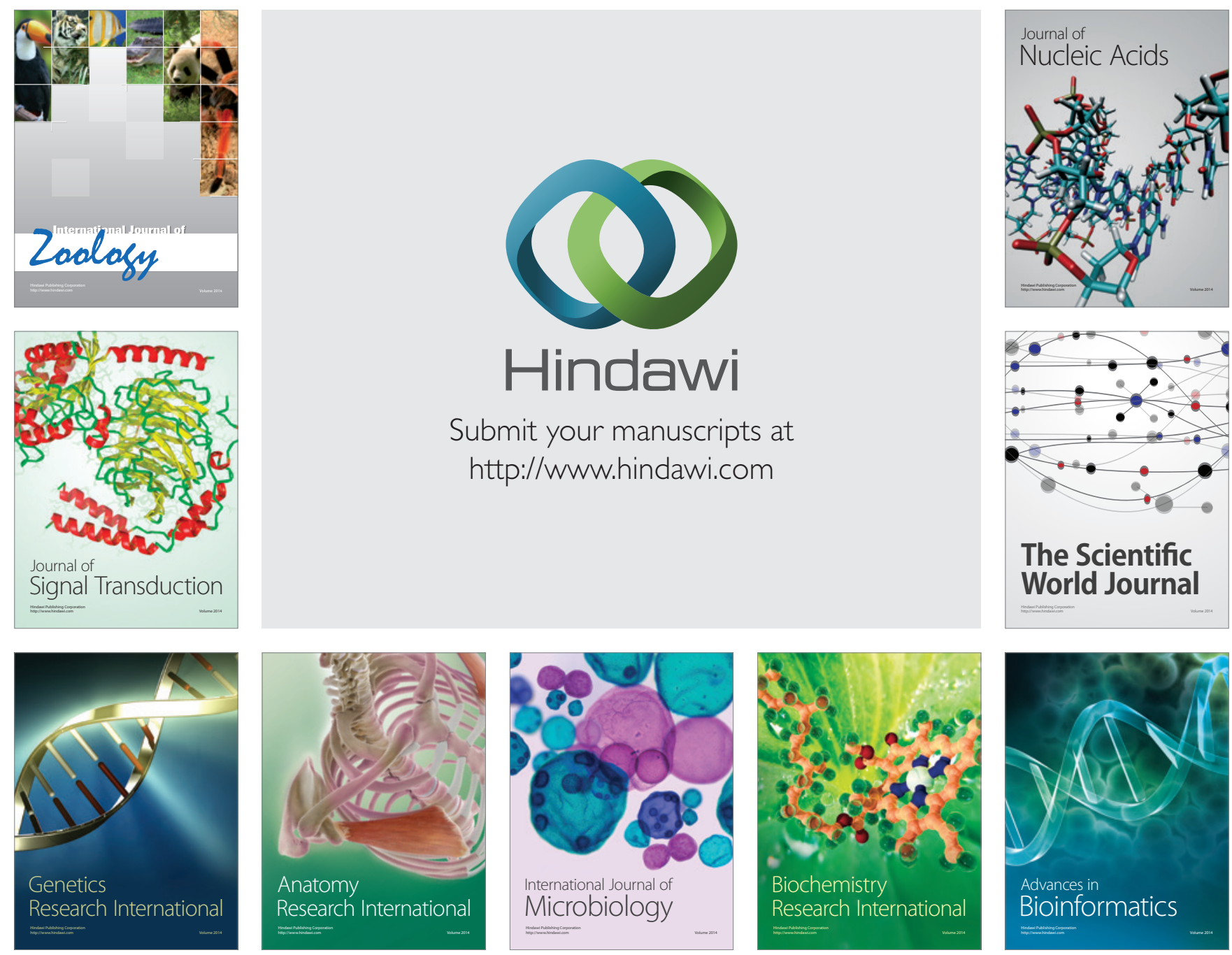

The Scientific World Journal
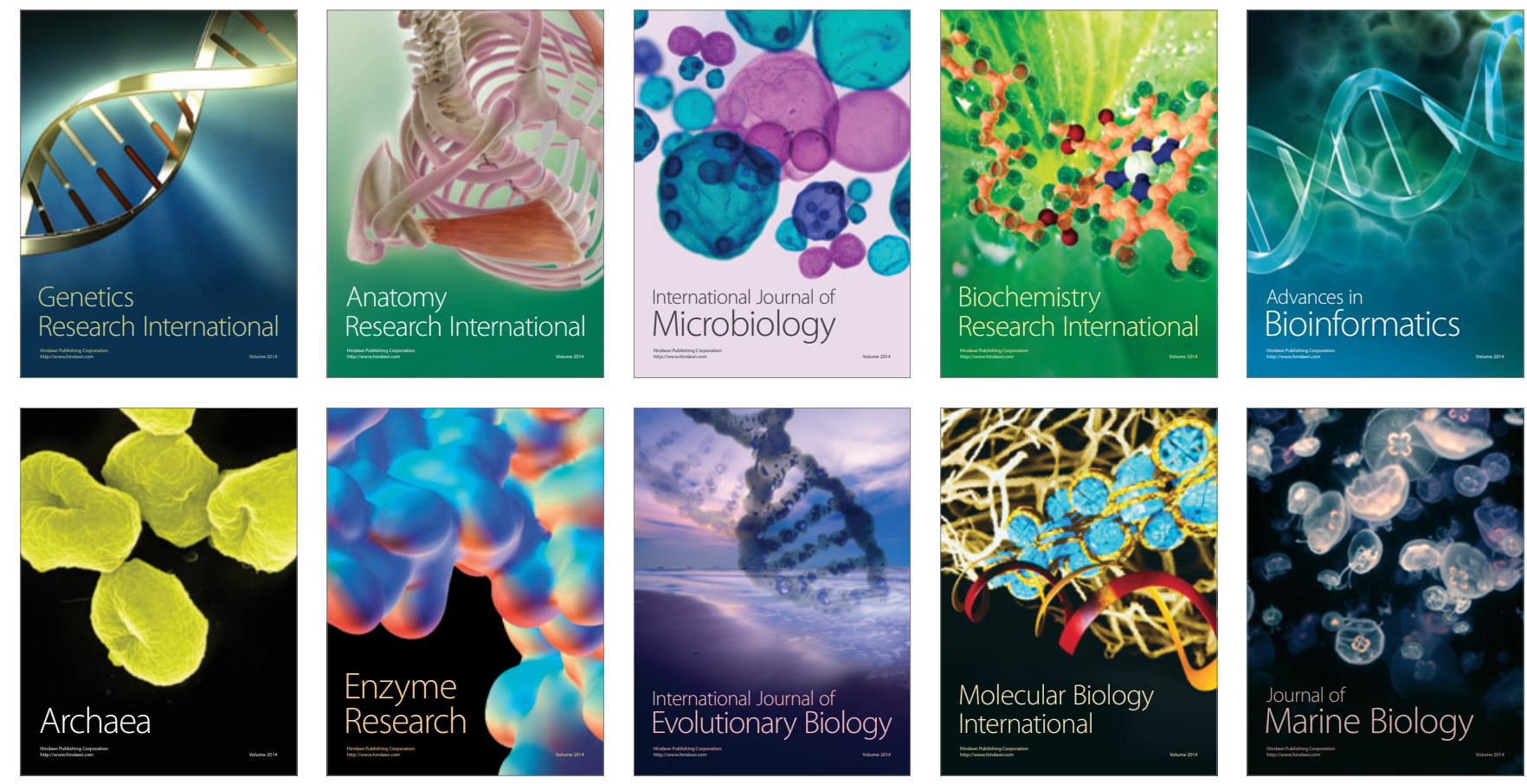